\title{
Airborne sound insulation of new composite wall structures
}

\author{
Yonka Ivanova ${ }^{1,2^{*}}$, Todor Partalin ${ }^{3}$, Luben Lakov ${ }^{4}$, and Bojidar Jivov ${ }^{4}$ \\ ${ }^{1}$ Sofia University, Faculty of Physics \\ ${ }^{2}$ Institute of Mechanics-BAS, Sofia, Bulgaria \\ ${ }^{3}$ Sofia University, Faculty of Mathematics and Informatics, Sofia, Bulgaria \\ ${ }^{4}$ Institute of Metal Science, Equipment and Technologies with Hydroaerodynamics Centre \\ "Acad. A. Balevski" - BAS, Sofia, Bulgaria
}

\begin{abstract}
Protection against noise is one of the essential requirements of the European Construction Product directive. In buildings, airborne sound insulation is used to define the acoustical quality between rooms. In order to develop wall structures with optimal sound insulation, an understanding of the physical origins of sound transmission is necessary. To develop a kind of knowledge that is applicable to the improvement of real walls and room barriers is the motive behind this study. The purpose of the work is to study the sound insulation of new composite wall structure.
\end{abstract}

\section{Introduction}

An important problem in the design, construction and operation of buildings is the achievement of energy efficiency and good sound insulation of housing and industrial constructions. One of the possible approaches to solving the problem is the use of composite sound and heat insulating materials to meet the requirements of the existing standards. At present, various insulation materials are found: cellular concrete products, foamed glass products, flammable and combustible polystyrene boards (EPS, XPS, etc.), mineral and glass wools with low water resistance, structural polystyrene, etc. [1]. Alternative composite insulation materials with good mechanical properties and low cost, obtained with recycled waste products are in process of developing.

\section{Development of new composite materials based on glass- foam granules}

A team of Institute of Metal Science, Equipment and Technologies "Acad. A. Balevski" Sofia, Bulgaria improved the technology for the production of foam glasses and developed a model for the production of composite heat and sound insulating materials made of glassfoam [2]. The developed technology is innovative as it recycles glass wastes. The

\footnotetext{
*Corresponding author: yonka@imbm.bas.bg
} 
developed composite material meets European requirements for fire safety [3] and is claimed by patents $[4,5]$.

Experimental specimens are made of 5 to $20 \mathrm{~mm}$ glass-foam granules made from glass waste and a bonding agent in the form of an aqueous dispersion colloidal silicate based system of Portland cement, zeolite, air-entraining addition for concrete and water. The introduction of the zeolite modifying addition into the composition of the binder increases the physical-mechanical performance. Experimental quantities of modifying additive, granule sorting techniques, excess liquid phase separation, different drying temperatures, and composite block box were performed to provide a material with good physical and mechanical performance for non-bearing walls and barriers. Various monolithic composite blocks have been developed. Figure 1 presents a photo of the composite wall model, made from glass-foam granules.

The aim of the present work is to study the sound insulation properties of the developed innovative materials with and without glass foam, but with an identical ratio of the other components. A sandwich panel is also designed that is developed from an inner layer of the composite and front and outside layers of waterproof screed. The results are compared with the ytong building material. Figure 2 shows a photo of sandwich panel, made of glass-foam granulated composite with external waterproof screeds.

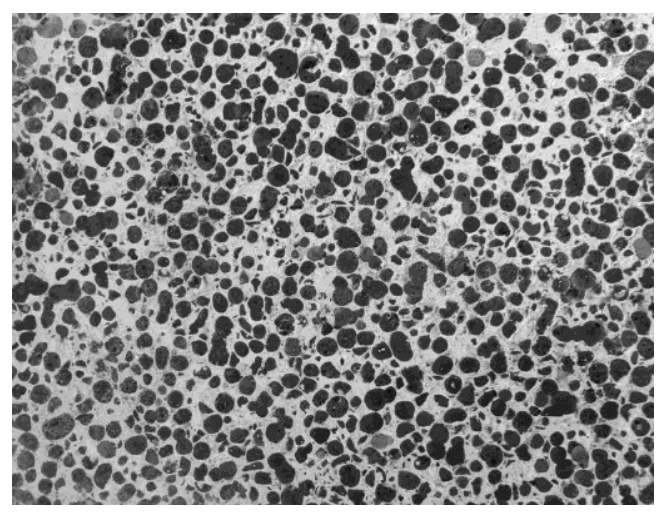

Fig. 1. Composite wall model with glass-granulated granules

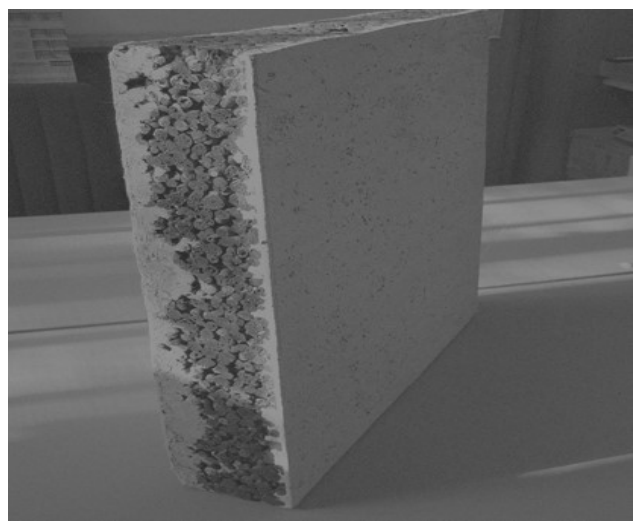

Fig.2.

granulated composite with waterproof screeds

Sandwich panel, made of glass-foam 


\section{Methodology of acoustic studies}

The acoustic measurements are carried out according to the procedures for field measurements of airborne sound insulation between two cameras (fig.3) [6-9]. The sound source camera contains one loudspeaker that creates a uniform sound field. The reference microphone measures the pressure of incident sound wave. Another microphone, placed in the receiving camera measures the pressure of the sound wave passed through the test specimen.

The sound pressure measurements $\mathrm{L}(\mathrm{dB})$ in the two cameras (rooms) are carried out in two modes:

1. Using a sinusoidal signal supplied to the single frequency speakers in octave bands $63,125,250,500,1000,2000,4000,8000 \mathrm{~Hz}$ and sound pressure measurements L (dB) with microphones in both chambers at each detected frequency. The recording of the sound level in the cameras is done with the RFT 00024 sounder.

2. By using a broadband signal generated by a sweep generator in the 65 to $10000 \mathrm{~Hz}$ frequency band that is fed to the loudspeaker, and the sound pressure measurements L (dB) of the sounding waveform passing through the sample with microphones, subsequent recordings and signal processing (spectral analysis).

The coefficient of sound insulation $\mathrm{R}$ is determined by the dependence [6-9]:

$$
R=L_{1}-L_{2},(\mathrm{~dB})
$$

where $\mathrm{L}_{1}$ and $\mathrm{L}_{2}$ are the measured sound pressure levels respectively in the camera with the sound source and the receiving camera.

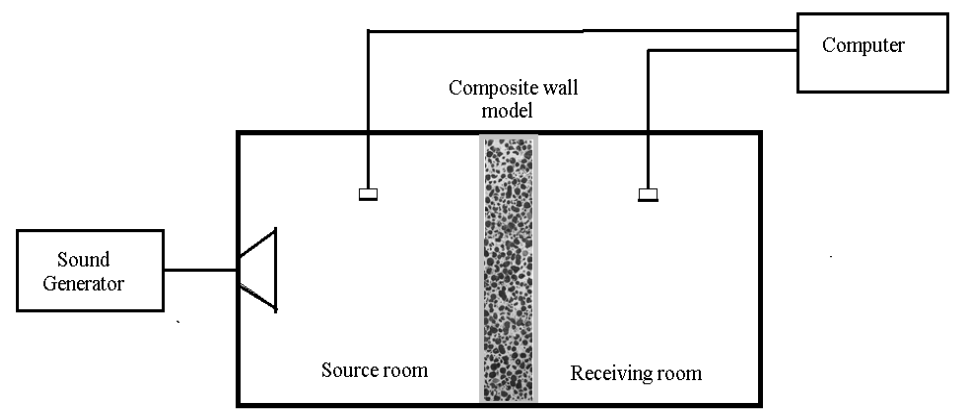

Fig.3 Schema of sound insulation measurements

\section{Results and Discussion}

Figures 4 and 5 show the results of the acoustic measurements for the developed composite panel with glass-foam granules and the non-granular composite material realized as described above in two modes: measured at individual frequencies and in the all frequency range. It can be seen that higher sound insulation properties possess glass-foam granules composite material. 


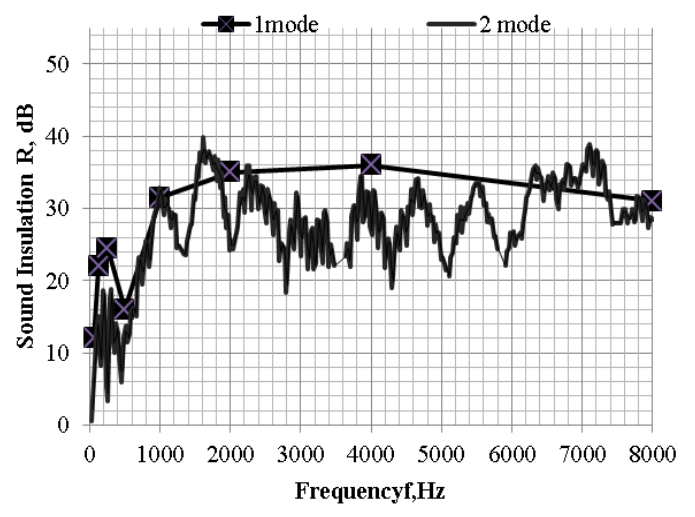

Fig.4.Dependence of sound insulation on frequency for composite materials based on glass-foam granules (GGCM)

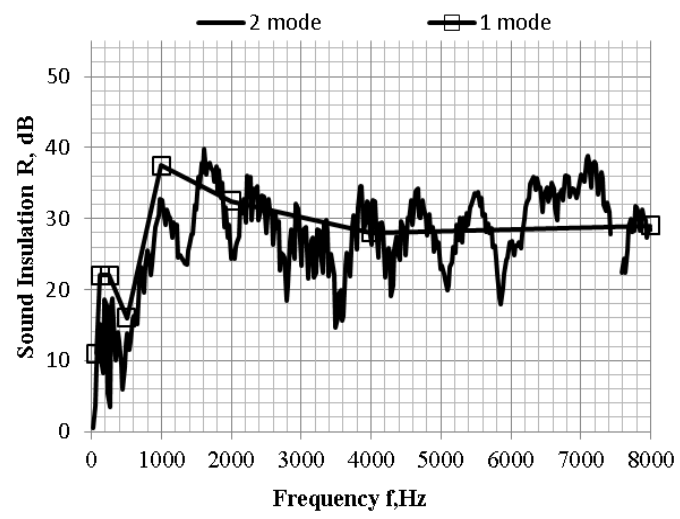

Fig. 5. Dependence of sound insulation on frequency for composite materials without glass-foam granules (NGCM)

Figure 6 compares the results for the composite wall model with glass granules (GGCM) and the reference panel without granules (NGCM) obtained at single frequency measurements. On the same figure are given the results for the sandwich composite panel with waterproof screeds (SP) and for ytong.

The mean value of sound insulation over the entire frequency range is $\mathrm{R}=30 \mathrm{~dB}$ for the innovative composite material and $\mathrm{R}=28 \mathrm{~dB}$ for the material without glass-foam granules, $\mathrm{R}=36 \mathrm{~dB}$ for the sandwich panel with waterproof coatings and $\mathrm{R}=33 \mathrm{~dB}$ for ytong. Comparing the results it can be seen that higher sound insulation properties possess sandwich panel consisted from glass granules composite material and waterproof coatings. 


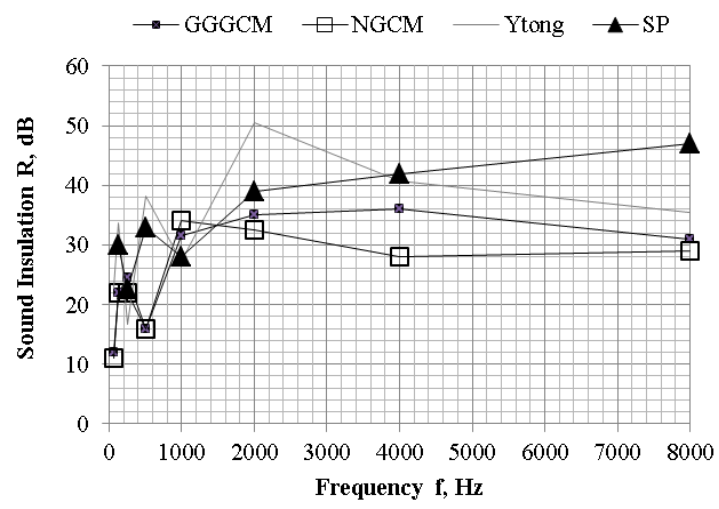

Fig. 6. Dependences of sound insulation on frequency for composite materials with (GGGCM) and without glass-foam granules (NGCM), composite panel with a waterproof coatings on their external sides (SP) and ytong.

\section{Conclusion}

The paper presents the results of sound insulation properties of innovative composite materials from glass foam granules and binder in the form of an aqueous dispersion colloidal system on a silicate basis as well as composite panels with waterproof coatings on their external sides.

The designed composite materials have suitable mechanical properties, good soundinsulation ability and could be used as sound insulated partitions and non-bearing walls in buildings.

The developed panels are considered to be potentially applicable for the construction of sound and thermal insulated non-porous interior partitions and external insulation of residential and industrial buildings and would extend the product scope to market for building materials.

\section{References}

1. D. Nazyrski, Building insulations (Sofia 2004).

2. L. Lakov, K.Toncheva, B. Jivov, S. Rafailov, S.Yordanov, Proc.of Intern.Conf. on Civil Eng.Des.and Const., 15-17 September 2016, Varna, Bulgaria (2016)

3. EU Regulation № 305/2011-2013

4. Patent № 111891/19.12.2014

5. Patent № 112126/27.10.2015

6. F. Fahy, Foundation of Engineering Acoustics (Elsevier Academic Press, San Diego, 2005)

7. Y. Ivanova, V. Vassilev, P. Djondjorov, Str. Djoumaliisky, Bulg.Chem. Commun. 42, $1-8$ ( 2015)

8. V. Hongisto, Airborn sound insulation of wall structures-measurement and prediction methods (Doct. Dissert, Helsinki University of Technology, Helsinki 2000)

9. M. Prascevic, D.Cvetkovic, D. Mihajlov, Facta Univers, Arch and Civ Engin, 10, 2, 155-167 (2012) 